\title{
Relationships Between Achievement Emotions, Motivation and Language Learning Strategies of High, Mid and Low English
}

\section{Language Achievers*}

\author{
TAN Jun-ming \\ Beijing Normal University-Hong Kong Baptist University United International College \\ Zhuhai, Guangdong, China
}

\begin{abstract}
Overseas research has shown that achievement emotions have direct relationships with "achievement outcome” and "achievement activities". The purpose of the present study aimed to compare the relationships between achievement emotions, motivation, and language learning strategies of high, mid and low achievers in English language learning at an international university in a southern province in China. Quantitative data were collected through a questionnaire survey of 74 (16 males, 58 females) TESL major students. Results indicated that students in general experienced more positive than negative achievement emotions; more intrinsically rather than extrinsically motivated to learn English; and quite frequently used a variety of learning strategies to overcome their learning difficulties. However, Year Four low-achievers experienced more negative achievement emotions. They seldom used metacognitive, affective and social learning strategies, and they had lower degrees of intrinsic motivation. Implications for institutional support for at risk students are discussed.
\end{abstract}

Keywords: achievement emotions, motivation, language learning strategies, English language achievement, English learning

\section{Introduction}

In China, many students may have experienced unhealthy negative emotions during their exam-oriented learning processes. The Chinese teaching system for preparing the College Entrance Exam focuses on teacher-centered mode, which means that teachers provide specific guidance for students to learn. However, when these students enter into the university, they have to re-adapt to a different way of learning which emphasizes self-directed and self-regulated learning. In an English-only learning environment, in particular, university students may feel too overwhelmed to adjust their learning and emotions in face of these challenges.

Pintrich and Groot (1990) studied the relationship between emotions with performance outcome and their impact on motivation. It was revealed that students' negative emotions including learning-related anxiety or boredom can reduce students' learning interest and lower their intrinsic motivation towards learning (Pintrich \&

\footnotetext{
* Acknowledgements: I would like to take this opportunity to express my deepest gratitude to my supervisor, Dr. Irene Y. Y. Fung, for her guidance and support. I would also like to thank all the participants from Teaching English as a Second Language Majors, who were willing to help me complete the questionnaires.

TAN Jun-ming, Bachelor of Arts (Honours) in Teaching English as a Second Language, Division of Humanities and Social Sciences, Beijing Normal University-Hong Kong Baptist University United International College.
} 
Groot, 1990). In the long run, it is difficult for demotivated students to persist with their learning. Furthermore, students who lack motivation and stimulation are less likely to apply deeper processing strategies to enhance their learning effectiveness (Pintrich \& Groot, 1990).

Hence, those students who are not motivated to engaging in learning usually employ non-effective learning strategies and have poor English achievement. Seeing their English grade plummeting exam by exam, they are likely to be trapped in a vicious cycle. If they cannot overcome these problems in time, they will continually suffer psychologically, physically and academically. Yet, these problems are often neglected by educators. In fact, there are certain ways to minimize or even prevent these problems if they are promptly found.

The research focus of the present study was to investigate whether the participating university students can achieve their English learning through managing their emotions, motivation and learning strategies. Specifically, the study aims to compare the relationships between achievement emotions, motivation, and language learning strategies of high-, mid- and low-achievers of English language learning in an English-only international university in China. The following two research questions guided the present study:

$R Q 1$. What is the general situation of and relationship between students' achievement emotions, motivation and language learning strategies with English language achievement?

$R Q 2$. Are there any differences between high, mid and low achievers in terms of these relationships?

\section{Literature Review}

\section{Achievement Emotions}

The term of achievement emotions refers to a kind of emotions that have direct relationships with "achievement outcome” and "achievement activities" (Pekrun, 2006, p. 316). They can be divided into positive emotions (e.g., example, enjoyment, hope, pride, and relief) and negative emotions (e.g., anger, anxiety, hopelessness, shame, and boredom) (Pekrun, Goetz, Frenzel, \& Perry, 2005, p. 4).

\section{Motivation}

Motivation can be classified into intrinsic and extrinsic motivation. Intrinsic motivation means that an individual performs an action simply because of enjoyment and self-satisfaction. Hence, an intrinsically motivated student is willing to undertake English learning for experiencing the inherent pleasure and satisfaction (ZHAO, 2012). In contrast, extrinsic motivation means an action that is performed primarily for some instrumental ends (Abrar-ul-Hassan, 2013). For example, learners will be motivated to engage in second language learning for getting a good grade. Students with extrinsic motivation experience less pleasure and emotional involvement because they are stimulated to engage in the academic activities for responding to external benefits (ZHAO, 2012).

In fact, students who are extrinsically motivated are relatively passive because their learning progress is likely to be at a standstill if they do not have sufficient external rewards (ZHAO, 2012). In contrast, students with intrinsic motivation can experience more sustainable pleasure because they work in response to positive feelings such as enjoyment and satisfaction.

\section{Language Learning Strategies}

Language learning strategies are the processes and actions taken by language learners to help them to learn or use a language more effectively (Cohen, 2011). They are commonly classified into (i) cognitive 
strategies—which involve comprehending and producing text, (ii) metacognitive strategies—which are used for organizing the learning process, (iii) compensation strategies—which can be applied effectively to overcoming the lack of specific knowledge, (iv) affective strategies - which are used for managing emotions and (v) social strategies—which involve seeking help from others (Souriyavongsa et al., 2013).

\section{Conceptual Framework}

A conceptual framework for this study was devised on the basis of a literature review on the relationships between achievement emotions, motivation, language learning strategies and English achievement (see Figure 1).

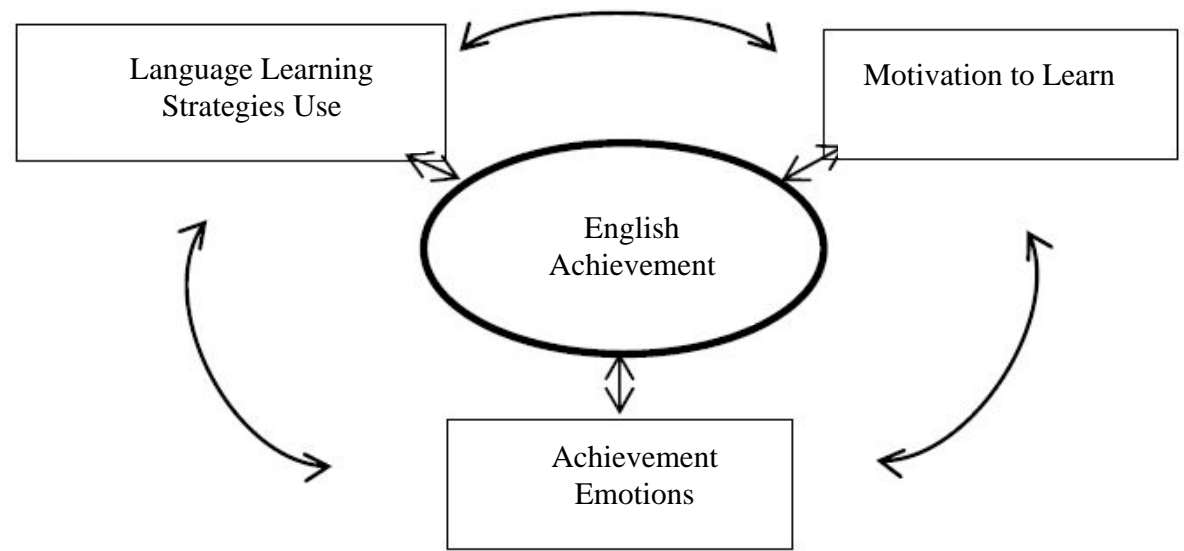

Figure 1. Relationships between language learning strategies, motivation, achievement emotions and English achievement.

The Relationship Between Achievement Emotions and Motivation to Learn. Through stimulating orientation towards the specific goal and intention related to emotions, the effects of emotions on motivation include triggering, sustaining and reducing these feelings (Pekrun et al., 2002). For instance, the enhancement of intrinsic learning motivation can be triggered by positive emotions such as learning enjoyment, whereas motivation can be activated by negative emotions such as hopelessness and boredom (Pekrun et al., 2002). On the other hand, negative emotions like anxiety, anger and shame can serve as a reinforcer strengthening certain types of extrinsic motivation (Pekrun et al., 2002). Specifically, extrinsic motivation can be stimulated by task-related anger for overcoming the difficulties or achievement motivation that can be triggered by anxiety and shame for avoiding failure (Pekrun et al., 2002).

The Relationship Between Achievement Emotions and Language Learning Strategies Use. In terms of the relationship between achievement emotions and language learning strategies, positive achievement emotions tend to associate with more flexible and deep-processing learning strategies use (Pekrun et al., 2002). These include elaboration, organization, evaluation and metacognition, whereas negative achievement emotions tend to associate with more rigid learning strategies use, such as rote learning (Pekrun et al., 2002).

The Relationship Between Learning motivation and Language Learning Strategies Use. Motivation and language learning strategies are strongly related to each other. Learners with stronger motivation to learn are usually active learners because they tend to more frequently use a variety of learning strategies to help "make learning easier, faster, more enjoyable, more self-directed, more effective, and more transferable to new situations" (Oxford, 1990, p. 8). According to Pintrich and Groot (1990), students who were intrinsically 
motivated to learn the materials would choose to apply different learning strategies and became more self-regulated.

The Relationship Between Achievement, Motivation, Learning Strategies Use and Achievement Emotions. More recent research on emotions in the academic domain has revealed that achievement emotions play significant roles in academic achievement. Specifically, students' ultimate success could be predicted by students' positive emotions (Pekrun et al., 2007). Previous research findings about motivation showed that intrinsic motivation ties with students' performance through linking to the use of self-regulated strategies (Pintrich \& Groot, 1990). A number of authors have considered the effects of learning strategies on academic achievement. Aydin (2003) showed that the use of strategy was highly correlated with academic achievement. According to Aslan (2009), employing more learning strategies was positively linked to students' success level in learning English. However, successful and unsuccessful learners differ in the quality rather than the quantity of their strategies use because successful learners often use different combinations of strategies suitable for specific tasks (Kaylani, 1996).

Therefore, in this study, it was hypothesized that students with high achievement have stronger intrinsic learning motivations, more frequently use effective language learning strategies and experience more positive emotions. In contrast, students with low achievement have stronger extrinsic learning motivation, less frequently use effective language learning strategies and experience more negative emotions.

\section{Methodology}

\section{Participants}

Seventy-four (16 male and 58 female) Years 2-4 TESL (Teaching English as a Second Language) major students from an international university in a southern province in Guangdong Province in China participated in the present questionnaire survey study. Their English abilities were not lower than 110 out of 150 in order to pass the general entrance requirement of this university.

\section{Instrument}

A 61-item questionnaire was designed for use in the present study. It contained four parts: individual background, achievement emotions, English learning motivation and English language learning strategies use. In Part I, information about the respondents' latest English GPA was collected so as to classify them into high-, mid- and low-achievers in the English course. In Part II, a 25-item achievement emotions subscale was adapted from the Achievement Emotions Questionnaire (Pekrun, Frenze, Goetz, \& Perry, 2005). This part was designed to measure students' English learning related emotions including positive emotions (enjoyment, hope and pride) and negative emotions (anger, anxiety, shame, hopelessness and boredom). Part III contained a motivation subscale with 15 items adapted from ZHAO (2012) for ascertaining respondents' intrinsic and extrinsic learning motivation orientations. In both Parts II and III, a five-point Likert scale was used with scores of 1 (strongly disagree), 2 (disagree), 3 (neutral), 4 (agree) and 5 (strongly agree). Finally, Part IV was a language learning strategies use subscale, consisting of 21 items adapted from the Strategy Inventory for Language Learning (Oxford, 1990) for identifying respondents' use of English learning strategies. A five-point Likert scale was used to show the frequency of using cognitive, compensation, metacognitive, affective and social learning strategies with scores: 1 (never), 2 (rarely), 3 (sometimes), 4 (often) and 5 (very often). 


\section{Procedure}

The data collection procedure began in the third week of the first semester of 2015-2016 academic year. The author administered the questionnaire survey during their major class break time. Voluntary participation in this survey invited. Confidentiality of personal information was assured. It took about 10 minutes for a respondent to complete the questionnaire. From the completed 100 questionnaires, 74 were considered valid and used for data analysis.

\section{Results}

\section{Relationships Between Achievement Emotions, Motivation, Language Learning Strategies Use and English Language Achievement}

Pearson product correlation coefficient was used to determine the relationships between the variables. The results showed that positive emotions and English language achievement were associated with each other significantly $(r=0.378, p<0.01)$. However, there was a significant negative correlation between negative emotions and English achievement $(r=-0.507, p<0.01)$.Intrinsic motivation was found to have significant positive correlation with English achievement $(r=0.293, p<0.01)$, whereas extrinsic motivation was found to be significantly associated with English achievement in a negative direction $(r=-0.375, p<0.01)$. Metacognitive strategies use had medium significant positive correlations with students' English language achievement $(r=0.363, p<0.01)$.

Table 1

Correlations Between Achievement Emotions, Motivation and Language Strategies Use With English Language Achievement

\begin{tabular}{|c|c|c|c|c|c|c|c|c|c|}
\hline \multirow[t]{2}{*}{$\mathrm{R}$} & \multicolumn{2}{|c|}{ Achievement emotions } & \multicolumn{2}{|c|}{ Motivation } & \multicolumn{5}{|c|}{ Language strategies use } \\
\hline & +ive & -ive & Intr & Extr & Cogn & Compn & Mcogn & Aff & Soc \\
\hline Eng. Ach & $0.378 * *$ & $-0.507 * *$ & $0.293 * *$ & $-0.375^{* *}$ & 0.102 & 0.153 & $0.363 * *$ & $0.223 *$ & $0.358 * *$ \\
\hline
\end{tabular}

Notes. ** Correlation is significant at the 0.01 level (2-tailed). * Correlation is significant at the 0.05 level (2-tailed).

Similarly, both affective and social strategies were significantly positively correlated with English learning achievement $(r=0.233, p<0.05 ; r=0.358, p<0.01$ ), the correlations were small and medium, respectively. However, no significant relationships were found between English language achievement and cognitive strategies as well as compensation strategies.

According to Cohen (1998), correlation range was divided into three categories: small ( $r=0.10$ to 0.29 ), medium ( $r=0.30$ to 0.49 ) and large ( $r=0.50$ to 1.0$)$. Table 1 shows the correlations between these variables. Positive emotions and intrinsic motivation were significantly positively correlated with English language achievement, whereas negative emotions and extrinsic motivation had significantly negative correlation with English language achievement. Additionally, metacognitive, affective and social strategies had significant positive correlation with English language achievement. With regard to cognitive and compensation strategies, they had no significant correlation with English language achievement. Most importantly, negative emotions, had greatest correlation coefficients on English academic achievement compared with learning motivation and learning strategies. In other words, it was the strongest predictor of English academic performance.

\section{Between-Group Differences in These Relationships}

Descriptive data showed that participants in general reported having experienced high frequency of 
positive than negative emotions, strong intrinsic rather than extrinsic motivation to learn English and quite frequently used a variety of learning strategies to overcome their learning difficulties. However, results of further analyses showed that there were some significant between-group differences.

Between-Group Differences by Achievement Level. For conducting between-group analyses, the participants were classified into three groups: high-, mid- and low-achievers, according to their latest university English GPA levels. Those who achieved A to B + levels were considered as high-achievers, B to B-, mid-achievers, and $\mathrm{C}+$ or below, low-achievers. As shown in Table 2, a large percentage of the high achievers (83.8\%) reported experiencing high degrees of positive achievement emotions whereas only about $10 \%$ of them reporting experiencing negative achievement emotions related to their English learning. Most of them (77\%) were found to be highly intrinsically motivated to learn English whereas only $13.5 \%$ of them were found having high degrees of extrinsic motivation to learn English. Further, the majority of them reported quite frequently using language learning strategies, especially, metacognitive strategies (79.7\%), affective strategies (50\%), and social strategies (83.8\%), to facilitate their learning process.

In contrast, only $4.1 \%$ of low achievers experienced high degrees of positive achievement emotions while nearly $78.4 \%$ of them reporting high degrees of negative achievement emotions. Most of them (70.3\%) were more extrinsically to learn English whereas only $8.1 \%$ of them were found having high degrees of intrinsic motivation. Moreover, they were found seldom using language learning strategies to control over their English learning, metacognitive strategies (10.8\%), affective strategies (24.3\%), and social strategies (8.1\%), in particular.

Table 2

Students’ Achievement Emotions, Motivation And Language Strategies Use (Frequency Percentage)

\begin{tabular}{|c|c|c|c|c|c|c|c|c|c|}
\hline \multirow[t]{2}{*}{ Achievers } & \multicolumn{2}{|c|}{$\begin{array}{c}\text { Achievement } \\
\text { emotions \% }\end{array}$} & \multicolumn{2}{|c|}{ Motivation \% } & \multicolumn{5}{|c|}{ Language strategies use \% } \\
\hline & +ve & -ve & Intr. & Extr. & Cogn. & Compn. & Mcogn & Aff. & Soc. \\
\hline Low & 12.10 & 78.40 & 8.10 & 70.30 & 25.7 & 29.70 & 10.80 & 24.30 & 8.10 \\
\hline Mid & 4.10 & 10.80 & 14.90 & 16.20 & 25.7 & 21.70 & 9.50 & 25.70 & 8.10 \\
\hline High & 83.80 & 10.80 & 77.00 & 13.50 & 48.6 & 48.60 & 79.70 & 50.00 & 83.80 \\
\hline
\end{tabular}

Results of Analysis of Variance (ANOVA) showed significant differences between the three groups on the three measures of academic emotions, motivation and language learning strategies use. Table 3 summarizes these ANOVA results. In respect of achievement motivation, low-achievers were found having significantly higher degrees of negative emotions, $F(2,72)=11.00, p<0.05$, and lower degrees of positive emotions, $F$ $(2,72)=6.21, p<0.05$, compared with both mid- and high-achievers.

As for motivation, significant group differences were found on the measure of intrinsic motivation measure. Low-achievers were found to be significantly less intrinsically motivated to learn English, compared with both mid- and high-achievers, $F(2,72)=3.29, p<0.05$. However, no such significant differences were found on the extrinsic motivation measure, $F(2,72)=2.18, p>0.05$.

With regard to language learning strategies use, significant between-group differences were found on the measure of metacognitive strategies use, $F(2,72)=5.12, p<0.05$; affective strategies use, $F(2,72)=5.34, p<$ 0.05 ; and social strategies use, $F(2,72)=4.15, p<0.05$. Low-achievers were found significantly less frequently using these strategies than mid- and high-achievers. However, no such significant differences were found on the other two measures: cognitive strategies use, $F(2,72)=0.66, p>0.05$; and compensation strategies use, $F$ $(2,72)=0.10, p>0.05$. 
Table 3

Between-Group Differences By Achievement Level

\begin{tabular}{|c|c|c|c|c|}
\hline & Low achiever means (S.D.) & Mid achiever means (S.D.) & High achiever means (S.D.) & $F$-value \& $p$-value \\
\hline \multicolumn{5}{|c|}{ Achievement Emotions } \\
\hline Positive & $3.36(0.72) *$ & $3.81(0.42) *$ & $3.97(0.61) *$ & $F(2,72)=6.21, p=0.00$ \\
\hline Negative & $2.79(0.60) *$ & $2.44(0.56) *$ & $1.98(0.47) *$ & $F(2,72)=11.00, p=0.00$ \\
\hline \multicolumn{5}{|l|}{ Motivation } \\
\hline Intrinsic & $3.52(0.74) *$ & $3.79(0.47) *$ & $3.90(0.65) *$ & $F(2,72)=3.29, p=0.03$ \\
\hline Extrinsic & $2.82(0.60)$ & $2.46(0.55)$ & $2.28(0.88)$ & $F(2,72)=2.18, p=0.12$ \\
\hline \multicolumn{5}{|c|}{ Language Learning Strategies Use } \\
\hline Cognitive & $3.22(0.48)$ & $3.28(0.40)$ & $3.40(0.67)$ & $F(2,72)=0.66, p=0.52$ \\
\hline Compensation & $3.35(0.57)$ & $3.61(0.60)$ & $3.64(0.65)$ & $F(2,72)=0.10, p=0.90$ \\
\hline Metacognitive & $2.96(0.54) *$ & $3.25(0.36) *$ & $3.50(0.73) *$ & $F(2,72)=5.12, p=0.01$ \\
\hline Affective & $2.89(0.82) *$ & $3.29(0.52) *$ & $3.47(0.90) *$ & $F(2,72)=5.34, p=0.03$ \\
\hline Social & $3.51(0.79) *$ & $3.70(0.49) *$ & $3.90(0.66) *$ & $F(2,72)=4.15, p=0.02$ \\
\hline
\end{tabular}

*Significant difference at the 0.05 confidence level.

Between-Group Differences by Year Level. ANOVA results (see Table 4) showed that Year 4 students experienced significantly higher degrees of negative achievement emotions than Years 3 and 2 students, $F$ $(2,72)=3.56, p<0.05$, and significantly lower degrees of positive achievement emotions than Years 3 and 2 students did, $F(2,72)=3.91, p<0.05$. Year 4 students also had significantly lower degrees of intrinsic motivation than Years 3 and 2 students did, $F(2,72)=4.55, p<0.05$, but no significant differences were found on the extrinsic motivation measure. Year 4 students were also found significantly less frequently used three types of language learning strategies: metacognitive strategies, $F(2,72)=3.77, p=0.03$;affective strategies, $F$ $(2,72)=4.25, p=0.02$; and social strategies, $F(2,72)=6.84, p=0.000$, compared with Years 3 and 2 students.

Table 4

Between-Group Differences By Year Level

\begin{tabular}{|c|c|c|c|c|}
\hline & Year two means (S.D.) & Year three means (S.D.) & Year four means (S.D.) & $F$-value \& $p$-value \\
\hline \multicolumn{5}{|c|}{ Achievement emotions } \\
\hline Positive & $3.88(0.69) *$ & $3.61(0.48) *$ & $3.44(0.68) *$ & $F(2,72)=3.91, p=0.02$ \\
\hline Negative & $2.20(0.56) *$ & $2.45(0.65) *$ & $2.58(0.68) *$ & $F(2,72)=3.56, p=0.02$ \\
\hline \multicolumn{5}{|l|}{ Motivation } \\
\hline Intrinsic & $3.85(0.74) *$ & $3.62(0.43) *$ & $3.33(0.69) *$ & $F(2,72)=4.55, p=0.01$ \\
\hline Extrinsic & $2.43(.80)$ & $2.58(.66)$ & $2.55(.63)$ & $F(2,72)=0.35, p=0.70$ \\
\hline \multicolumn{5}{|c|}{ Language learning strategies use } \\
\hline Cognitive & $3.28(0.61)$ & $3.18(0.43)$ & $2.99(0.72)$ & $F(2,72)=1.94, p=0.15$ \\
\hline Compensation & $3.60(0.65)$ & $3.61(0.68)$ & $3.48(0.56)$ & $F(2,72)=0.46, p=0.64$ \\
\hline Metacognitive & $3.37(0.60) *$ & $3.30(0.40) *$ & $3.02(0.63) *$ & $F(2,72)=3.77, p=0.03$ \\
\hline Affective & $3.36(0.85) *$ & $3.24(0.57) *$ & $2.88(0.74) *$ & $F(2,72)=4.25, p=0.02$ \\
\hline Social & $3.93(0.72) *$ & $3.71(0.64) *$ & $3.32(0.58) *$ & $F(2,72)=6.84, p=0.000$ \\
\hline
\end{tabular}

*Significant difference at the 0.05 confidence level.

In summary, Year 4 students were more likely to experience less positive emotions but more negative emotions, less intrinsically motivated to learn English, and less frequently used metacognitive, affective and social learning strategies compared with Years 3 and 2 students. 


\section{Conclusion}

The results of the present study confirm the hypotheses that students with high achievement have stronger intrinsic learning motivations, more frequently use effective language learning strategies and experience more positive achievement emotions and that students with low achievement have stronger extrinsic learning motivation, less frequently use effective language learning strategies and experience more negative emotions. These findings are consistent with the previous studies in the literature (Artino, 2010; Mega et al., 2014; Pekrun et al., 2007; Printrich, \& Groot, 1990).

Overall, Year 4 low-achievers were found to experience the greatest negative achievement emotions, with the lowest degrees of intrinsic motivation and the least frequently use of metacognitive, affective and social learning strategies. This group of low-achievers should be the least likely to enjoy their studies or be resourceful to employ strategies to facilitate their learning so as to improve their achievement. One possible explanation might be that those low-achievers did not ask for help from others when they started to experience negative achievement emotions towards English learning. Nor would they be likely to employ a flexible combination of effective language learning strategies to facilitate their language learning. If these problems were not addressed in time, a vicious cycle would come into play when more and more negative achievement emotions accumulated with time.

An implication for institutional support is that it is crucial to provide help to the at-risk group at each year level. It might be useful to provide workshops for enhancing students' awareness of ways for managing their achievement emotions, for example, by seeking help or advice from peers as well as instructors on better use of learning strategies or other supports to improve their achievement.

Another implication is that it is important for low-achievers to address their academic, motivational and emotional problems promptly rather than letting them get worse and worse with time. In this participating university, there is already a Mentor Caring Programme and a Student Tutor Programme for Year 1 students to help them adapt to the university life easily and quickly. The work of these two programmes could be extended to Year 2 students if resources were allowed. For identifying students who might be as risk, a student questionnaire for each year level at the beginning of an academic year could be administered for assessing students' degree of achievement emotions, motivation and language learning strategies use.

Interpretation of the results of the present study needs to be cautious because of its limitations of using a small sample of participants, involving only one major programme in one institution, as well as the limitations of using self-report English achievement data. Further research should include student interviews to achieve a deeper understanding of those at-risk students about their perceptions of difficulties in their studies as well as the kind of institutional supports they hope to get so as to enhance their learning.

\section{References}

Abrar-ul-Hassan, S. (2013). A study of the motivational patterns of learners of English for academic and professional purposes. TESOL Journal, 5(1), 32-56.

Aslan, O. (2009). The role of gender and language learning strategies in learning English. (Master's thesis). Retrieved from http://etd.lib.metu.edu.tr/upload/12611098/index.pdf

Artino, A. R. (2010). Emotion regulation. In S. Goldstein and J. Naglieri (Eds.), Encyclopedia of child behaviour and development (pp. 1236-1238). Heidelberg, Germany: Springer.

Cohen, A. (2011). Strategies in learning and using a second language (2nd ed.). Longman. 
Ginsburg, G., \& Bronstein, P. (1993). Family factors related to children’s intrinsic/extrinsic motivational orientation and academic performance. Child Development, 64(5), 1461-1461.

Kaylani, C. (1996). The influence of gender and motivation on EFL learning strategy use in Jordan. In R. Oxford (Ed.), Language learning strategies around the world: cross-cultural perspectives (Technical Report \#13) (pp. 75-88). Honolulu: University of Hawai'i, Second Language Teaching and Curriculum Center.

Mega, C., Ronconi, L., \& Rossana, D. B. (2014). What makes a good student? How emotions, self-regulated learning and motivation contribute to academic achievement. Development Review, 106(1), 121-131.

Ogundokun, M. O. (2010). Emotional intelligence and academic achievement: The moderating influence of age, intrinsic and extrinsic motivation. The African Symposium, 10(2), 127-140. Retrieved from https:/www.ncsu.edu/aern/TAS10.2/TAS10.2Ogundokun.pdf

Oxford, R. L. (1990). Language learning strategies: What every teacher should know. Boston: Heinle \& Heinle.

Oxford, R. L., Judd, C., \& Giesen, J. (1998). Relationships among learning strategies, learning styles, EFL proficiency, and academic performance among secondary school students in Turkey. Tuscaloosa, Alabama, USA: University of Alabama.

Pekrun, R., Goetz, T., Titz, W., \& Perry, R. (2002). Academic emotions in students' self-regulated learning and achievement: A program of qualitative and quantitative research. Educational Psychologist, 37(2), 91-106.

Pekrun, R., Goetz, T., Frenzel, A. C., \& Perry, R. P. (2005). Academic emotions questionnaire (AEQ). User's manual. Munich, Germany: Department of Psychology, University of Munich.

Pekrun, R. (2006). The control-value theory of achievement emotions: Assumptions, corollaries, and implications for educational research and practice. Educational Psychology Review, 18, 315-341.

Pekrun, R., Frenzel, A., Goetz, T., \& Perry, R. (2007). The control-value theory of achievement emotions: An integrative approach to emotions in education. Emotion in Education, 13-36.

Pekrun, R., Goetz, T., Frenzel, A. C., Barchfeld, P., \& Perry, R. P. (2005). Measuring emotions in students' learning and performance: The Academic Emotions Questionnaire (AEQ). Contemporary Education Psychology, 36, 36-48.

Pintrich, P. R., \& Groot, E. V. (1990). Motivational and self-regulated learning components of classroom academic performance. Journal of Educational Psychology, 82(1), 33-40.

Rebecca, L. (2003). Language learning style and strategies: An overview. Learning Styles and Strategies, 1-25. Retrieved from http://web.ntpu.edu.tw/ language/workshop/read2.pdf

Souriyavongsa, T., Abidin, M., Sam, R., Lai Mei, L., \& Aloysius, I. B. (2013). Investigating learning English strategies and English needs of undergraduate students at the National University of Laos. English Language Teaching, 6(10), 57-71.

ZHAO, L. (2012). Investigation into motivation types and influences on motivation: The case of Chinese non-English majors. English Language Teaching, 5(3), 100-122. 